\title{
EL VOTO IGUAL EN EL SISTEMA ELECTORAL ESPAÑOL
}

\author{
Lorena Chano Regaña \\ Profesora de Derecho Constitucional, \\ Universidad de Extremadura
}

Cómo citar este artículo / Citation: Chano Regaña, Lorena. (2021).

El voto igual en el sistema electoral español.

Palacios Romeo, F. y Cebrián Zazurca, E. (coords.)

Elección y representación: una conjunción compleja. Perspectivas y problemas de los

regímenes electorales en España,

Colección Obras colectivas, Fundación Manuel Giménez Abad, Zaragoza.

DOI: https://doi.org/10.47919/FMGA.OC21.0302

SUMARIO: I. PLANTEAMIENTO DEL PROBLEMA - II. LA PARTICIPACIÓN POLÍTICA A TRAVÉS DEL DERECHO A UN VOTO IGUAL - III. LA MODULACIÓN LEGÍTIMA DEL DERECHO A UN VOTO IGUAL EN ARAS DE LA PROPORCIONALIDAD DEL SISTEMA - IV. LOS SISTEMAS ELECTORALES PROPORCIONALES - V. LOS RESULTADOS REALES EN EL VALOR DE VOTO - VI. CONCLUSIONES

\section{PLANTEAMIENTO DEL PROBLEMA}

El presente trabajo ofrece un análisis crítico desde una perspectiva constitucional del valor del voto en el sistema electoral proporcional español. El objetivo final es constatar las carencias del actual régimen jurídico electoral y las fisuras en la relación de representatividad entre gobernantes y gobernados recogidas en el texto constitucional.

El problema que se plantea no es ninguna novedad en la crítica del sistema electoral español ni pretende serlo, es más bien una constatación de una realidad presentada desde una perspectiva constitucional y respetuosa con los 
postulados de la Constitución española de 1978 (en adelante, CE) ${ }^{1}$. Tradicionalmente $\mathrm{y}$, sobre todo en períodos electorales, se juzga y critica el valor del voto, pero pocas veces tales críticas se efectúan desde una perspectiva evaluativa de la legitimidad constitucional del sistema electoral. Las críticas comúnmente se centran en las ventajas e inconvenientes de unos $u$ otros sistemas, pero no cuestionan si el sistema es respetuoso con los postulados del texto constitucional. Esto es lógico si tenemos en cuenta que el sistema que venimos utilizando, plasmado en la Ley Orgánica del Régimen Electoral General de 1985 (en adelante, LOREG) ${ }^{2}$, apenas ha sufrido cambios desde el Real Decreto-Ley de las elecciones de $1977^{3}$, esto es, desde las primeras elecciones democráticas y constituyentes en España. Por ello, es quizá lógico que no nos planteemos su constitucionalidad sino más bien sus ventajas e inconvenientes para concluir si es (o no) la mejor opción con respecto al derecho comparado.

Lo que pretendemos con este trabajo es analizar si efectivamente existe un derecho al voto igual constitucionalmente garantizado, si ese derecho al voto igual quiebra como consecuencia del sistema electoral que empleamos en España, y si, como consecuencia de esa quiebra estamos rompiendo también, o, disminuyendo en alguna medida, la relación de representatividad que debe mediar entre representantes y representados. En concreto, las preguntas que nos planteamos son: $1^{\circ}$ ) ¿Existe un derecho constitucionalmente garantizado a un voto igual? $2^{\circ}$ ) ¿Los votos valen efectivamente igual?, es decir, ¿tienen el mismo valor cuantitativo en la materialización de votos en escaños? $\mathrm{Y}, 3^{\circ}$ ) ¿Quiebra o se merma la relación de representatividad entre electores y elegidos por la utilización de un sistema proporcional basado en la fórmula D'hont?

Para responder a estas preguntas a partir de una metodología jurídica, se examinará: primero, el fundamento constitucional del derecho de la ciudadanía a un voto igual; segundo, la legitimidad constitucional de la modulación que el legislador realiza a través de las normas electorales del citado derecho para operar en el sistema electoral proporcional español; y, tercero y último, los efectos que se producen sobre el valor de los votos en la realidad aplicando la

\footnotetext{
${ }^{1}$ Constitución española (BOE núm. 311 de 29 de diciembre de 1978).

2 Ley Orgánica 5/1985, de 19 de junio, del Régimen Electoral General (Boletín Oficial del Estado, en adelante, BOE núm. 147 de 20 de junio de 1985).

${ }^{3}$ Real Decreto-Ley 20/1977, de 18 de marzo, sobre Normas Electorales (BOE núm. 70 de 23 de marzo de 1977), [disposición derogada].
} 
fórmula D'hont de proporcionalidad. El contexto político actual y los resultados de las últimas elecciones generales en España servirán de ejemplo para ilustrar la paradoja entre la configuración constitucional del voto y los efectos reales que produce la legislación electoral en el valor del sufragio.

Comenzaremos por contextualizar, como presupuestos previos, el reconocimiento constitucional de la igualdad política y las implicaciones de un sistema electoral proporcional.

\section{LA PARTICIPACIÓN POLÍTICA A TRAVÉS DEL DERECHO A UN VOTO IGUAL}

La igualdad de todas las personas está formalmente reconocida en el art. 14 $\mathrm{CE}$, donde se establece que: "Los españoles son iguales ante la ley sin que pueda prevalecer discriminación alguna por razón de nacimiento, raza, sexo, religión y opinión o cualquier otra condición o circunstancia personal o social". Aunque el precepto alude a "los españoles", el Tribunal Constitucional se cuidó de precisar en una primera jurisprudencia de los años ochenta que en el artículo $14 \mathrm{CE}$ se consideraban incluidas todas las personas, con independencia de que fueran españolas o no. El art. 13.1 CE permite que en los términos que establezcan los tratados y la ley se puedan extender los derechos y libertades públicas reconocidos en el Título I de la CE a las personas extranjeras ${ }^{4}$. El legislador no puede limitar la titularidad de los derechos de quienes ostenten una nacionalidad foránea, simplemente puede establecer algunos condicionantes para su ejercicio ${ }^{5}$. Y, de igual modo, la doctrina del Tribunal Constitucional hace extensiva a las personas jurídicas todos aquellos derechos que por su naturaleza sean susceptibles de ser ejercidos por ellas ${ }^{6}$.

Este predicamento del Tribunal Constitucional sobre la igualdad en el disfrute

\footnotetext{
${ }^{4}$ Los derechos vinculados a la dignidad humana (art. 10.1 CE) no admiten un tratamiento jurídico diferente, con independencia de que la literalidad del texto constitucional utilice la expresión "Ios españoles". Así lo afirmó el Tribunal Constitucional en STC 107/1984, de 23 de noviembre, FFJJ 3 y 4; STC 99/1985, de 30 de septiembre, FJ 2; STC 115/1987, de 7 de julio, FJ 3; y, STC 137/2000, de 29 de mayo, FJ 1.

${ }^{5}$ Sobre el alcance de los condicionantes para su ejercicio, vid. la STC 236/2007, de 7 de noviembre, FJ 4, que declaró inconstitucionales los preceptos de la Ley Orgánica 4/2000, de 11 de enero, sobre derechos y libertades de los extranjeros en España y su integración social (BOE núm. 10 de 12 de enero de 2000), los cuales exigían la residencia legal en España de las personas extranjeras para ejercer los derechos de asociación, reunión, manifestación y sindicación.

${ }^{6}$ STC 100/1993, de 22 de marzo, FJ 2 y STC 139/1995, de 26 de septiembre, FJ 5.
} 
de los derechos y libertades en base a la dignidad humana, no alcanza a la participación política consagrada en el art. 23.1 CE, ni al derecho de acceso en condiciones de igualdad a los cargos públicos (art. 23.2 CE). El ejercicio de la participación política está reservado a quienes disfrutan del estatuto jurídico de la nacionalidad española. De modo que existe una igualdad política cuya titularidad sólo ostenta la ciudadanía española con carácter exclusivo y excluyente. Esta afirmación debe ser matizada al interpretarse en conjunción con el art. 13.2 CE, que permite, en virtud del principio de reciprocidad, que las personas extranjeras puedan ejercer el derecho de sufragio activo en las elecciones municipales ${ }^{7}$.

Así las cosas, el derecho de participación política consagrado en el art. 23.1 CE reconoce a la ciudadanía "el derecho a participar en los asuntos públicos, directamente o por medio de representantes, libremente elegidos en elecciones periódicas por sufragio universal". Nada dice de forma expresa sobre el reconocimiento de un derecho a un voto igual.

Las menciones específicas a la igualdad en el voto las encontramos en los arts. 68.1 y $69.2 \mathrm{CE}$, donde se exige que la elección de Diputados y Diputadas; y, Senadores y Senadoras, respectivamente, sea mediante voto "libre, igual, directo y secreto". El resto de apartados de los arts. 68 y 69 CE aluden al criterio demográfico y al de representación proporcional para configurar el reparto de votos en escaños.

En este orden de ideas y a pesar de que el art. 23.1 CE no cita de forma explícita a la igualdad en la participación de los asuntos públicos, el precepto debe entenderse como una proyección de la igualdad del art. $14 \mathrm{CE}$. La interpretación conjunta del art. 23.1 CE con el art. 139.1 CE ("Todos los españoles tienen los mismos derechos y obligaciones en cualquier parte del territorio del Estado") permite afirmar que la elección libre de los representantes a través del sufragio debe ser igual en todo el territorio y para todas las personas. De la interacción de ambos preceptos se desprende el fundamento constitucional del derecho a un voto igual en todo el territorio del Estado. Así se ha admitido en esta última década por el propio Tribunal Constitucional, quien en el año 2011 pronunció una sentencia en un proceso de control de la constitucionalidad donde afirmó la existencia de la "igualdad en el sufragio" y el

\footnotetext{
${ }^{7}$ Esto es así desde la reforma operada en el art. 13.2 CE (BOE núm. 207 de 28 de agosto de 1992) para poder suscribir el Tratado de la Unión Europea firmado en Maastricht el 7 de febrero de 1992.
} 
"derecho a la igualdad en el voto" para toda la ciudadanía ${ }^{8}$. La afirmación se basaba en la interpretación conjunta del art. 23.1 CE con el art. 139.1 CE y en conexión con los arts. 68.1 y 69.2 CE. Con posterioridad, el Tribunal Constitucional ha reiterado esta aseveración en una ocasión más, al hilo de tres recursos de amparo electorales acumulados sobre la posible vulneración de los derechos de sufragio activo y pasivo en las elecciones a la Junta General del Principado de Asturias en $2012^{9}$.

En concreto, el Tribunal Constitucional configura en estas sentencias el derecho al voto igual en los siguientes términos:

“(...) el principio de igualdad en el sufragio o, en otras palabras, la garantía de un sufragio igual, superada la etapa de una concepción formal, se viene entendiendo en el constitucionalismo contemporáneo como una exigencia sustancial de igualdad en el voto que impone tanto el igual valor numérico como el igual valor de resultado del sufragio. Aunque no opera de la misma manera en los sistemas electorales mayoritarios que en los proporcionales, basta con señalar, en lo que ahora interesa, que supone en estos últimos, además de un idéntico valor numérico del voto, que todos los votos hayan de contribuir de manera semejante o similar en la asignación de escaños y, por tanto, en la conformación del órgano representativo"10.

El hecho de que el Tribunal Constitucional no haya afirmado expresamente el derecho al voto igual en todo el territorio hasta el año 2011, no significa que tácitamente no existiera este derecho.

El principio de igualdad en el voto ha sido promulgado internacionalmente, como puede constatarse en el art. 21.3 de la Declaración Universal de Derechos Humanos proclamada por la Asamblea General de Naciones Unidas en París en $1948^{11}$ y en otras declaraciones internacionales de derechos

\footnotetext{
${ }^{8}$ STC 19/2011, de 3 de marzo, FJ 9. La Sentencia es resolutoria de un recurso de inconstitucionalidad interpuesto por el Grupo Parlamentario Popular en relación a la Ley $12 / 2007$, de 8 de noviembre, por la que se adecúa la Ley 5/1986, de 23 de diciembre, electoral de Castilla-La Mancha (BOE núm. 193 de 13 de agosto de 2012).

${ }^{9}$ STC 105/2012, de 11 de mayo, FJ 16. La Sentencia estima la vulneración del derecho de sufragio activo de los electores, resolviendo la improcedencia de una nueva convocatoria electoral "al existir garantías estadísticas sólidas para concluir que el cómputo de los votos controvertidos no es determinante del resultado final de la elección".

${ }^{10}$ STC 19/2011, de 3 de marzo, FJ 9, párrafo $3^{\circ}$. (La cursiva es mía).

${ }^{11}$ Resolución de la Asamblea General de Naciones Unidas núm. 217 A (III), de 10 de diciembre de 1948. [En línea]. Recuperado de: https://www.un.org/es/universal-declaration-human-rights/ (consultado el 15 de noviembre de 2020).
} 
posteriores en el tiempo, como por ejemplo, en el art. 25 del Pacto Internacional de Derechos Civiles y Políticos de $1966^{12}$; en el art. 3 del Protocolo Adicional de 1952 al Convenio Europeo para la protección de los Derechos Humanos y de las Libertades Públicas ${ }^{13}$; y en el art. 39 de la Carta de Derechos Fundamentales de la Unión Europea, vinculante desde diciembre de $2009^{14}$.

Además de los textos citados, especial relevancia para la interpretación constitucional del derecho de participación política, tiene el "Código de Buenas Prácticas en materia electoral" aprobado en el seno del Consejo de Europa el 23 de mayo de 2003. El Código recoge los "cinco principios del patrimonio electoral europeo", dentro de los cuales se incluye "la igualdad del sufragio", que supone "igual número de votos: en principio, cada votante tiene derecho a un voto; cuando el sistema electoral concede a los votantes más de un voto, cada votante tiene el mismo número de votos". E, "igual poder de voto: los escaños deberán repartirse por igual entre las circunscripciones"15.

En definitiva, de todo lo expuesto se colige que la igualdad en el voto implica: primero, igual valor numérico de cada voto; segundo, igual valor en el resultado del sufragio, es decir, que todos los votos concurren con el mismo valor numérico a la transmutación de votos en escaños ${ }^{16}$.

\footnotetext{
12 Instrumento de Ratificación de España del Pacto Internacional de Derechos Civiles y Políticos, hecho en Nueva York el 19 de diciembre de 1966 (BOE núm. 103 de 30 de abril de 1977).

${ }^{13}$ Resolución de 5 de abril de 1999, de la Secretaría General Técnica, por la que se hacen públicos los textos refundidos del Convenio para la protección de los derechos y de las libertades fundamentales, hecho en Roma el 4 de noviembre de 1950; el protocolo adicional al Convenio, hecho en París el 20 de marzo de 1952, y el protocolo núm. 6, relativo a la abolición de la pena de muerte, hecho en Estrasburgo el 28 de abril de 1983 (BOE núm. 108 de 6 de mayo de 1999).

${ }^{14}$ Diario Oficial de la Unión Europea (DOUE) núm. C-202 de 7 de junio de 2016 (última versión consolidada).

${ }^{15}$ Comisión Europea para la Democracia por el Derecho - Comisión de Venecia, Código de Buenas Prácticas en materia electoral. Directrices e informe explicativo, Coordinación de Comunicación Social - Tribunal Electoral del Poder Judicial de la Federación, México, 2011, pp. 16 y 32-36. [En línea]. Recuperado de:

https://www.te.gob.mx/sites/default/files/informacion_importante/2012/04/codigo_buenas_practi cas_pdf_18140.pdf (consultado el 15 de noviembre de 2020). Cfr. Álvarez Conde, E., "Los principios del derecho electoral", Revista del Centro de Estudios Constitucionales, núm. 9, 1991, pp. 9-37.

${ }^{16}$ En similares términos se han manifestado también en el derecho comparado. Como muestra, la doctrina del Tribunal Constitucional Federal Alemán. Cfr. BVerfGE, de 3 de julio de 2008, 2 BvC 1/07 y 2 BvC 7/07; y, BVerfGE, de 25 de julio de 2012, 2 BvF 3/11, 2 BvR 2670/11 y 2 BvE $9 / 11$. $Y$ en el controvertido caso italiano, con las recientes modificaciones de su sistema electoral y los pronunciamientos de inconstitucionalidad de la Corte Constitucional, cfr. Cecili, M., "El sistema electoral italiano: lo que el legislador hace, el Tribunal lo deshace", Revista de
} 
Así lo ha entendido también la doctrina cuando hablamos de sistemas electorales proporcionales:

"Con respecto a la diferenciación entre ambos sistemas, se ha especificado desde la doctrina y la jurisprudencia comparada que los sistemas mayoritarios reconocen el principio de igual valor del voto desde el punto de partida o meramente numérica, en cambio, en los sistemas electorales proporcionales se va mucho más allá, al tenerse en consideración, además, la igualdad en el valor de resultado. Por todo ello, la opción por estos últimos, en definitiva, persigue una fidedigna representación del electorado en relación con el voto emitido. Es más, se ha llegado a interpretar, por determinada jurisprudencia constitucional del Derecho comparado, que la opción jurídica de adoptar un sistema proporcional -la cual se efectúa con libertad por el legislador o por el legislador constituyente-, obliga a respetar ese tipo de representación"17.

La igualdad en el sufragio se configura así, como un derecho al voto igual y como una garantía "de igualdad en el valor del voto en todo el territorio". Llegados a este punto, cabe preguntarse qué repercusiones tiene afirmar que existe un derecho a un voto igual en el territorio y que este derecho está garantizado constitucionalmente. Sobre todo, porque no nos ha pasado desapercibido el hecho de que el Tribunal Constitucional no hable de "igual" valor en el resultado del voto, sino que señala que "todos los votos hayan de contribuir de manera semejante o similar en la asignación de escaños"18. La tensión entre esta concepción normativa del derecho al voto igual y la realidad material del valor del voto viene dada por la consideración del territorio; el territorio dividido en circunscripciones electorales para el cómputo de los votos es el elemento de distorsión que rompe la ecuación de representatividad en los sistemas electorales proporcionales.

\footnotetext{
Derecho Político, núm. 106, 2019, pp. 271-272.

${ }^{17}$ San Segundo Manuel, J.M., El sistema electoral: una reforma obligada, Editorial Bosch, Madrid, 2016, p. 27. Asimismo, sobre esta afirmación, cfr. Soriano Díaz, R.L. y Alarcón Cabrera, C., "Las elecciones en España: ¿votos iguales y libres?", Revista de Derecho Político, núm. 114, 2001, pp. 115-130 y, particularmente, p. 122. Lázaro, A., "Proporcionalidad, territorialidad e igualdad en los sistemas electorales autonómicos", Revista Española de Derecho Constitucional, núm. 59, 2000, pp. 219-242. Y Trujillo, G., "El Estado y las Comunidades Autónomas ante la exigencia constitucional del voto igual", Revista Española de Derecho Constitucional, núm. 2, 1981, pp. 9-56 y, en concreto, pp. 22-23.

${ }^{18}$ STC 19/2011, de 3 de marzo, FJ 9, párrafo $3^{\circ}$. (La cursiva es mía).
} 


\section{LA MODULACIÓN LEGÍTIMA DEL DERECHO AL VOTO IGUAL EN ARAS DE LA PROPORCIONALIDAD DEL SISTEMA}

El derecho al voto igual, puede ser limitado por el legislador de la misma forma que el resto de derechos y de bienes constitucionales, siempre que exista una justificación objetiva y razonable, que persiga una finalidad legítima y que no produzca efectos excesivamente gravosos que impliquen el sacrificio de otro derecho o bien constitucional.

Aplicando esta doctrina justificadora de la quiebra de la igualdad formal, el Tribunal Constitucional ha admitido la modulación de la igualdad en el voto para dar cumplimiento a la exigencia de proporcionalidad y para asegurar la representación de determinados territorios poco poblados (art. 152.1 CE) ${ }^{19}$.

En estas lindes, el Tribunal Constitucional ha declarado que la exigencia constitucional y estatutaria de garantizar la proporcionalidad del sistema electoral es un criterio orientativo y tendencial que en modo alguno presenta un carácter absoluto. Así:

"No se trata, en ningún caso, de la exigencia de un sistema puro de proporcionalidad, sino que, por el contrario, la proporcionalidad es, más bien, una orientación o criterio tendencial, porque siempre, mediante su puesta en práctica, quedará modulada o corregida por múltiples factores del sistema electoral hasta el punto de que puede afirmarse que cualquier concreción o desarrollo normativo del criterio, para hacer viable su aplicación, implica necesariamente un recorte a esa 'pureza' de la proporcionalidad abstractamente considerada" 20 .

La proporcionalidad en cuanto a criterio orientativo o tendencia que debe perseguir como objetivo el sistema electoral, es un bien constitucionalmente protegido que admite la modulación por parte del legislador para preservar otros bienes también constitucionalmente protegidos que, conforme a la libertad configuradora del poder encargado de producir las normas, resulten de interés preponderante en la sociedad española. El Tribunal Constitucional ha incidido en sus argumentos sobre el hecho de que "el mandato constitucional y estatutario de que se arbitre un sistema de representación proporcional otorga

\footnotetext{
${ }^{19}$ STC 225/1998, de 25 de noviembre, FJ 6.

${ }^{20}$ STC 75/1985, de 21 de junio, FJ 5 y STC 19/52011, de 3 de marzo, FJ 3. Cfr. Garrorena, A., "Tribunal Constitucional y sistema electoral de las Comunidades Autónomas. Una desafortunada jurisprudencia", Revista española de derecho constitucional, núm. 83, 2008, pp. 243-275.
} 
al legislador un amplio margen en la configuración de los elementos del sistema que deben, tendencialmente, buscar su consecución" ${ }^{21}$, lo cual no impide que en la configuración del resto de elementos del sistema se sacrifique en algún grado la proporcionalidad de la representación para satisfacer otros objetivos constitucionales debidamente justificados y coherentes con el desarrollo del proceso electoral.

Entre esos elementos inciertos que configura libremente el legislador y que pueden afectar a la proporcionalidad, se encuentran: el número mínimo y máximo de representantes parlamentarios según los criterios demográficos ${ }^{22}$, la fórmula matemática concreta que se siga en la trasposición de los votos en escaños en relación al reparto autonómico en la circunscripción ${ }^{23}$ o la barrera electoral para concurrir a la distribución de los escaños ${ }^{24}$.

Este argumento, traducido en términos de igualdad supone que el valor del voto puede variar en cada territorio afectando a la proporcionalidad en aras de reconocer la representación mínima de alguna circunscripción. Formalmente la igualdad jurídica del resultado del voto (esto es, de su valor en el cómputo de los escaños) se afecta pudiendo llegar a resultados insatisfactorios para los agentes de la actividad política (partidos políticos y cuerpo electoral). El Tribunal Constitucional admite la afectación de la igualdad formal en la justificación de querer lograr una igualdad material que reconoce la representatividad de territorios que, de otra forma, difícilmente podrían lograr una cuota de poder en la institución legislativa. El territorio es, por tanto, el elemento distorsionador que sustenta la base constitucional de la proclamación de la igualdad en el voto, y que lo modula en función de la realidad material de la provincia como circunscripción electoral, tanto en lo que respecta a su población, como en lo relativo a la distribución de la masa de votantes en las diferentes circunscripciones. De ahí que el Tribunal constitucional, a diferencia de la doctrina, propugne que el valor del voto en la trasposición de los escaños sea "semejante" o "similar", admitiendo cierto índice de desviación justificado en el logro de otros objetivos constitucionales.

En suma, la admisibilidad de este tipo de modulaciones por parte del Tribunal

${ }^{21}$ STC 19/52011, de 3 de marzo, FJ 3.

${ }^{22}$ STC 75/1985, de 21 de junio, FJ 5; STC 72/1989, de 20 de abril, FFJJ 2 y 2; STC 193/1989, de 16 de noviembre, FFJJ 3 y 4 ; y, STC 225/1998, de 25 de noviembre, FJ 7.

${ }^{23}$ STC 49/1992, de 2 de abril, FJ 2 y ATC 240/2008, de 22 de julio. Vid. también, Fernández Esquer, C., "Algunos problemas en la articulación jurídica de los sistemas electorales autonómicos", Revista de las Cortes Generales, núm. 97-99, 2016, pp. 327-357.

${ }^{24}$ STC 49/1992, de 2 de abril, FJ 3. 
Constitucional, exige: primero, constatar la existencia de un fin constitucionalmente legítimo; segundo, la adecuación de la modulación o restricción que se establezca para lograr el fin propuesto; $y$, tercero, la comprobación de que no existen otras modulaciones o medidas menos gravosas para lograr el mismo fin, siendo la limitación de la igualdad formal del voto $\mathrm{y}$, en su caso, de la proporcionalidad del sistema, adecuadamente ponderadas para lograr en su conjunto mayores beneficios que perjuicios en el proceso electoral. En definitiva, lo que se exige es que se supere el test de proporcionalidad $^{25}$ que viene utilizando el Tribunal Constitucional para admitir la limitación de los derechos fundamentales. Así lo ha declarado específicamente el Órgano y así lo ha aplicado en relación al voto igual en la STC 19/2011 ${ }^{26}$.

\section{LOS SISTEMAS ELECTORALES PROPORCIONALES}

La representación política de las sociedades democráticas se justifica tradicionalmente en el hecho cierto y consabido de que es imposible materialmente que toda la colectividad de un estado participe directamente en la elaboración de las leyes en el parlamento ${ }^{27}$, lo que hace necesario algún tipo de mecanismo de reducción de las voluntades particulares en una voluntad representativa de la colectividad.

Partimos de la base de que la voluntad social o general de la colectividad no existe: hay voluntades particulares e individuales de cada persona; pero son heterogéneas, diversas y complejas; por lo que la dinámica del Estado social y democrático contemporáneo, las reduce a través de la existencia del sistema electoral a una sola voluntad política que persigue fines de interés general. La fórmula de integración de las voluntades individuales no se produce a partir del reflejo proporcionado o la "reproducción a escala" de los colectivos en la institución legislativa $u$ órganos representativos ${ }^{28}$, sino a través de la

\footnotetext{
${ }^{25}$ Entendemos por tal, "el conjunto de criterios o herramientas que permiten medir y sopesar la licitud de todo género de límites normativos de las libertades, así como las de cualesquiera interpretaciones o aplicaciones de la legalidad que restrinjan su ejercicio, desde un concreto perfil o punto de mira: el de la inutilidad, innecesariedad y desequilibrio del sacrificio", Barnes, J., "El principio de proporcionalidad. Estudio preliminar", Revista Cuadernos de Derecho Público, núm. 5, 1998, p. 16. Para profundizar más en su uso por el Tribunal Constitucional, vid. González Beilfuss, M., El principio de proporcionalidad en la jurisprudencia del Tribunal Constitucional, Aranzadi, Madrid, 2015.

${ }^{26}$ STC 19/52011, de 3 de marzo, FFJJ 7 a 9.

${ }^{27}$ Laporta, F.J., "Sobre la teoría de la democracia y el concepto de representación política: algunas propuestas para debate", Doxa, núm. 6, 1989, pp. 121-123.

${ }^{28}$ Cfr. la postura clásica de Pitkin, H., El concepto de representación (traducción de Montoro
} 
instrumentalización de las necesidades sociales en una ideología de masas acotada en existencia de partidos políticos ${ }^{29}$.

El partido político es el primer elemento de reducción de la voluntad social, pero necesita combinarse con las reglas del sistema electoral para cumplir el objetivo de la representación política y que ésta a su vez estimule su "función dinámica" de interrelación entre gobernantes y gobernados mediante la integración en la actividad política de los intereses sociales y demandas ciudadanas $^{30}$. El sistema electoral es la fórmula a través de la cual se convierten los votos en escaños, haciendo efectivo el proceso de representación política en los regímenes constitucionales de forma periódica ${ }^{31}$.

El interrogante que nos planteamos ahora para contextualizar el valor del voto en España es cómo se conforma el voto representativo en el sistema electoral español. O, en otras palabras, cómo se conmuta el número de votos en escaños.

Lo ideal y preceptuado por la CE es que el sistema electoral sea efectivamente representativo y, además, proporcional. Sólo así se podrá dar cumplimiento a la relación de representatividad entre electores y elegibles que sustenta la legitimidad democrática del sistema político español ${ }^{32}$.

La exigencia de proporcionalidad en el sistema electoral español está recogida en los arts. 68 y 69 CE. Así, en el apartado 3 del art. 68 CE: "La elección se verificará en cada circunscripción atendiendo a criterios de representación proporcional". El texto constitucional divide electoralmente el territorio del Estado, estableciendo como circunscripción electoral la provincia (art. 68.2 CE). Asimismo, establece la periodicidad de las elecciones en cuatro años (arts. 68.4 y 69.6 CE); fija ciertos mínimos en el reparto de representantes parlamentarios (arts. 68.1 y 2; y, 69.2 y 3 CE); y, remite a la ley su concreción

Romero, R.), Centro de Estudios Políticos y Constitucionales, Madrid, 1985. También, Laporta, F.J., ob. cit., pp. 130-131.

${ }^{29}$ Criado de Diego, M., "El proceso constituyente español de 1977-78: un marco político insuficiente en la actualidad", en AA.VV., Por una asamblea constituyente. Una solución democrática a la crisis, Sequitur, Madrid, 2012, pp. 52-53. A mayor abundamiento, cfr. Vallès. J.M., Ciencia Política. Una introducción, Ariel, Madrid, 2010, pp. 361-378.

${ }^{30}$ Criado de Diego, M., "Sobre el concepto de representación política: lineamientos para un estudio de las transformaciones de la democracia representativa", Revista Derecho del Estado, núm. 28,2012 , pp. 78-92, donde se distingue entre la doble función dinámica y estática en la teoría clásica de la representación política.

${ }^{31}$ San Segundo Manuel, J.M., ob. cit., p. 25-26.

32 Cfr. Criado de Diego, M., Representación, estado y democracia, Tirant lo Blanch, Valencia, 2007, pp. 209-247. 
numérica. En cumplimiento de la remisión legislativa del texto constitucional, la LOREG convierte los votos en escaños a través de una fórmula denominada "fórmula $D$ 'Hont" ${ }^{33}$, que tiene un umbral mínimo de cómputo del $3 \%$ de los votos por circunscripción.

Según los debates parlamentarios constituyentes, la exigencia de proporcionalidad se basa en la experiencia del derecho comparado (Francia, Portugal, Bélgica) y en razones de justicia electoral que permiten a un mayor número de fuerzas políticas acceder al gobierno, lo que mejora la representatividad de los electores y garantiza la pluralidad democrática (art. 1.1 y 6 CE). Sin embargo, esa mayor afluencia de fuerzas políticas puede poner en peligro la gobernabilidad al resultar complicado llegar a acuerdos que permitan otorgar la confianza parlamentaria a una candidatura a la presidencia del Gobierno, como ha sucedido en las dos últimas elecciones generales (2016 y 2019), en las que se han celebrado dos procesos electorales en diciembre de 2015 y junio de 2016; y, dos en 2019 (abril y noviembre) hasta lograr la investidura del candidato a la presidencia del Gobierno.

A diferencia del sistema de circunscripción única en el que se cumple la máxima de "un ciudadano, un voto" operando el principio de mayoría en el cómputo de los de votos (sistema mayoritario), en nuestro sistema tenemos como circunscripción la provincia. En total el reparto de escaños se produce entre 52 circunscripciones con diferente extensión territorial y población.

Así, de los 350 escaños que fija el art. 162 de la LOREG para el Congreso, 102 tienen un reparto fijo: A cada una de las 50 provincias le corresponden dos diputados y a Ceuta y Melilla, uno a cada una. La LOREG prevé esta adjudicación para representar a los distritos menos poblados. El objetivo es evitar que los partidos se centren sólo en aquellos núcleos poblacionales mayoritarios. La mínima representación asegura un papel protagónico también a los territorios menos poblados.

Los otros 248 escaños se reparten de manera proporcional según el criterio demográfico. En cada convocatoria electoral, publicada en el BOE, se revisa el número de escaños que corresponde a cada provincia ya que en el trascurso de cuatro años -período habitual entre legislaturas- el dato de población puede variar. En el caso de las elecciones del 10 de noviembre de 2019 (10-N), los

\footnotetext{
${ }^{33}$ Cfr. Carreras Serra, F. y Vallès, J.M., Las elecciones. Introducción a los sistemas electorales, Blume, Barcelona, 1977.
} 
datos no habían variado respecto a las elecciones de 28 de abril del mismo año (28-A). A Soria, Ceuta y Melilla, las circunscripciones menos pobladas, les corresponden solo los escaños fijos (2, 1 y 1 respectivamente). A las circunscripciones más pobladas, Madrid, Barcelona y Valencia, les corresponden 37,32 y 15 escaños respectivamente ${ }^{34}$.

Según el art. 163 de la LOREG, en el reparto de escaños se desprecian aquellas candidaturas que no hubieran obtenido al menos el $3 \%$ de los votos válidos emitidos en la circunscripción. Las que superen tal barrera se ordenan por columnas de mayor a menor, dividiéndose sucesivamente el número de votos obtenidos "por 1, 2, 3, etc. hasta un número igual al de escaños correspondientes a la circunscripción (...). Los escaños se atribuyen a las candidaturas que obtengan los cocientes mayores en el cuadro, atendiendo a un orden decreciente."

El funcionamiento del Senado es diferente. Busca lograr el equilibrio en la representatividad territorial, al margen de la densidad de población, por lo que los electores pueden votar el número máximo de Senadores y Senadoras que le correspondan a cada circunscripción conforme al art. $69 \mathrm{CE}$, siendo "proclamados electos aquellos candidatos que obtengan mayor número de votos hasta complementar el de Senadores asignados a la circunscripción" (art.166.1, apartado b) de la LOREG).

A efectos del valor del voto en la conversión a escaños conforme al sistema proporcional español de cociente mayor, interesan los resultados del Congreso, que analizamos a continuación.

\section{LOS RESULTADOS REALES EN EL VALOR DE VOTO}

Las consecuencias del sistema proporcional basado en la fórmula D'Hondt en la designación de escaños en el Congreso se resume en que en las provincias menos pobladas los partidos necesitan menos votos para lograr un escaño. En las elecciones del 28-A, mientras que en Madrid para lograr un diputado se necesitaron 122.222 votos, en Teruel solo se necesitaron 26.027 votos. Los 3,81 millones de votantes de Madrid eligieron a treinta y siete Diputados y Diputadas mientras que los 79.427 votantes de Teruel eligieron a tres representantes. Ello implica que en una provincia menos poblada como Teruel

34 Fuente: Infoelectoral Gobierno de España. [En línea]. Recuperado de: http://www.infoelectoral.mir.es/ (consultado el 15 de noviembre de 2020). 
fundación

Manuel Giménez Abad

deEstudios Parlamentariosy del Estado Autonómico

el valor del voto es mucho mayor que en una muy poblada como Madrid. El sistema electoral español facilita que las provincias menos pobladas tengan más escaños que los que les corresponderían por número de habitantes.

En consecuencia, si un partido tiene repartidos sus votos en varias circunscripciones al operar a nivel nacional, puede obtener menos escaños que un partido con muchos apoyos en una sola provincia (por ejemplo, el caso del PNV en las elecciones del 28-A y de Teruel Existe en el 10-N).

A continuación, se expone el valor de los votos de cada partido en las últimas elecciones, el 10-N de 2019:

Tabla núm. 1: Valor en votos del escaño por partido político el 10-N

\begin{tabular}{|c|c|c|c|c|}
\hline Partido político & $\begin{array}{c}\text { Número } \\
\text { de votos }\end{array}$ & $\begin{array}{c}\text { Número } \\
\text { de } \\
\text { escaños }\end{array}$ & $\begin{array}{c}\text { Votos } \\
\text { por cada } \\
\text { escaño }\end{array}$ & $\begin{array}{c}\text { Votos } \\
\text { perdidos }\end{array}$ \\
\hline PSOE & 6.752 .983 & 120 & $\mathbf{5 6 . 2 7 5}$ & -4.807 \\
\hline PP & 5.019 .869 & 88 & $\mathbf{5 7 . 0 4 4}$ & -9.223 \\
\hline VOX & 3.640 .063 & 52 & $\mathbf{7 0 . 0 0 1}$ & -42.003 \\
\hline PODEMOS-IU & 3.097 .185 & 35 & $\mathbf{8 8 . 4 9 1}$ & -822 \\
\hline $\begin{array}{c}\text { ERC- } \\
\text { SOBIRANISTES }\end{array}$ & 869.934 & 13 & $\mathbf{6 6 . 9 1 8}$ & -1.108 \\
\hline CIUDADANOS & 1.637 .540 & 10 & $\mathbf{1 6 3 . 7 5 4}$ & +90.848 \\
\hline JXCAT-JUNTS & 527.375 & 8 & $\mathbf{6 5 . 9 2 2}$ & -5.619 \\
\hline EAJ-PNV & 377.423 & 7 & $\mathbf{5 3 . 9 1 8}$ & -12.063 \\
\hline EH BILDU & 276.519 & 5 & $\mathbf{5 5 . 3 0 4}$ & 9.608 \\
\hline MÁS PAIS & 579.035 & 3 & $\mathbf{1 9 3 . 0 1 2}$ & - \\
\hline CUP-PR & 244.754 & 2 & $\mathbf{1 2 2 . 3 2 7}$ & - \\
\hline CCA-PNC-NC & 123.981 & 2 & $\mathbf{6 1 . 9 9 1}$ & -6.841 \\
\hline NA+ & 98.448 & 2 & $\mathbf{4 9 . 2 2 4}$ & -4.586 \\
\hline BNG & 119.597 & 1 & $\mathbf{1 1 9 . 5 9 7}$ & - \\
\hline & & & & \\
\hline
\end{tabular}


fundación

Manuel Giménez Abad

deEstudios Parlamentariosy del Estado Autonómico

\begin{tabular}{|c|c|c|c|c|}
\hline PRC & 68.580 & 1 & $\mathbf{6 8 . 5 8 0}$ & +16.314 \\
\hline TERUEL EXISTE & 19.696 & 1 & $\mathbf{1 9 . 6 9 6}$ & - \\
\hline PACMA & 226.469 & 0 & - & - \\
\hline
\end{tabular}

Elaboración propia a partir de datos disponibles en: Infoelectoral Gobierno de España ${ }^{35}$

Sigue la exposición gráfica del valor en número de votos de cada escaño para cada provincia en las últimas elecciones, el 10-N de 2019:

Tabla núm. 2:

Valor en votos del escaño por provincia el 10-N

\begin{tabular}{|c|c|}
\hline $\begin{array}{c}\text { Provincia / } \\
\text { circunscripción }\end{array}$ & $\begin{array}{l}\text { Número de } \\
\text { votos por cada } \\
\text { escaño }\end{array}$ \\
\hline A Coruña & $84.667,75$ \\
\hline Álava & $44.341,50$ \\
\hline Albacete & 58.601 \\
\hline Alicante & $76.458,17$ \\
\hline Almería & $54.682,83$ \\
\hline Asturias & 89.523 \\
\hline Ávila & $34.026,33$ \\
\hline Badajoz & $68.065,50$ \\
\hline Barcelona & $97.513,78$ \\
\hline Burgos & $54.888,25$ \\
\hline Cáceres & 62.183 \\
\hline Cádiz & $74.173,56$ \\
\hline
\end{tabular}

35 Fuente: Infoelectoral Gobierno de España. [En línea]. Recuperado de: http://www.infoelectoral.mir.es/ (consultado el 15 de noviembre de 2020). 
fundación

Manuel Giménez Abad

deEstudios Parlamentariosy del Estado Autonómico

\begin{tabular}{|c|c|}
\hline Cantabria & $71.820,80$ \\
\hline Castellón & $62.678,60$ \\
\hline Ceuta & 37.991 \\
\hline Ciudad Real & $58.781,40$ \\
\hline Córdoba & $78.952,67$ \\
\hline Cuenca & $39.843,33$ \\
\hline Girona & $63.712,50$ \\
\hline Granada & $74.834,71$ \\
\hline Guadalajara & 47.569 \\
\hline Guipúzcoa & $68.687,67$ \\
\hline Huelva & $52.913,80$ \\
\hline Huesca & $41.771,33$ \\
\hline Illes Balears & $64.813,38$ \\
\hline Jaén & $77.383,20$ \\
\hline La Rioja & 45.208 \\
\hline Las Palmas & $68.131,50$ \\
\hline León & 72.900 \\
\hline Lleida & $56.413,75$ \\
\hline Lugo & $49.999,50$ \\
\hline Madrid & $102.222,89$ \\
\hline Málaga & $74.260,73$ \\
\hline Melilla & 33.758 \\
\hline Murcia & $76.908,40$ \\
\hline Navarra & $73.399,60$ \\
\hline Ourense & $48.130,75$ \\
\hline Palencia & $35.347,67$ \\
\hline Pontevedra & $82.312,43$ \\
\hline
\end{tabular}




\begin{tabular}{|l|l|}
\hline Salamanca & $52.661,50$ \\
\hline $\begin{array}{l}\text { Santa Cruz de } \\
\text { Tenerife }\end{array}$ & $73.783,43$ \\
\hline Segovia & 30.836 \\
\hline Sevilla & $93.542,25$ \\
\hline Soria & $26.038,50$ \\
\hline Tarragona & $69.698,67$ \\
\hline Teruel & $26.027,67$ \\
\hline Toledo & $66.151,67$ \\
\hline Valencia & $97.101,80$ \\
\hline Valladolid & $67.310,80$ \\
\hline Vizcaya & 85.870 \\
\hline Zamora & $36.881,67$ \\
\hline Zaragoza & 79.201 \\
\hline
\end{tabular}

Elaboración propia a partir de datos disponibles en: Infoelectoral Gobierno de España ${ }^{36}$

Como puede comprobarse el valor del voto por circunscripción presenta una desviación muy elevada que va desde los 102.222 votos necesarios en Madrid para lograr un escaño, a los apenas 26.000 votos que vale un escaño en Teruel o Soria, circunscripciones menos pobladas. Lo que supone que el voto en Soria o Teruel vale cinco veces más que en Madrid.

En resumen, nuestro sistema electoral se caracteriza por:

- Favorecer a las dos fuerzas políticas más votadas a nivel estatal, perjudicando al resto.

- Favorecer a los partidos políticos nacionalistas (o minoritarios) muy presentes en una Comunidad Autónoma frente a otros con mayor número de votos, pero dispersos en el territorio.

36 Fuente: Infoelectoral Gobierno de España. [En línea]. Recuperado de: http://www.infoelectoral.mir.es/ (consultado el 15 de noviembre de 2020). 
- Las provincias con escasa población están supra-representadas frente a las de mucha población que están infra-representadas.

- La barrera electoral del 3\% de votos excluye alrededor de 3.000 .000 de votos de partidos pequeños que no acceden a obtener escaño.

- Los índices de proporcionalidad son bajos si se analiza la pérdida de votos y se compara con otros sistemas electorales proporcionales del derecho comparado.

Por tanto, la proporcionalidad del sistema no opera como debiera representando de forma directa la elección de los votantes, sino que más bien opera una manipulación del voto que implica diferente valor según las siguientes circunstancias:

- En primer lugar, según al partido político que se vote, si es mayoritario o no.

- En segundo lugar, según la circunscripción en que se vote: atendiendo a la extensión del territorio y la población que lo ocupa.

\section{CONCLUSIONES}

Primera. Existe un derecho constitucionalmente garantizado al voto igual vinculado al territorio, que se disgrega en una doble consideración:

a) Igual valor numérico del voto.

b) Igual valor de resultado del sufragio.

En lo que respecta a esta segunda consideración, se ha constatado que la garantía constitucional del valor del resultado, según la doctrina del Tribunal Constitucional, no es igual sino "semejante" o "similar", admitiendo modulaciones con el objetivo de asegurar la representatividad de aquellos territorios menos poblados en cumplimiento de lo preceptuado en el art. 152.1 CE.

La doctrina del Tribunal Constitucional admite como constitucional la desviación en el valor del voto, partiendo de los siguientes postulados:

- La indefinición constitucional del sistema electoral, que remite al pertinente desarrollo legislativo.

- La libertad de configuración del legislador a la hora de definir el 
sistema electoral y la fórmula matemática para la distribución de escaños en el territorio.

- El carácter tendencial u orientativo de la exigencia de proporcionalidad, que admite variaciones sustanciales justificadas en la consecución de otros bienes constitucionalmente protegidos, como son la representatividad de las diversas zonas del territorio y el pluralismo político.

Segunda. El territorio es el elemento distorsionador que sustenta la base constitucional de la proclamación de la igualdad en el voto, y que lo modula en función de la realidad material de la provincia como circunscripción electoral. La tensión entre esta concepción dogmática-normativa del derecho al voto igual (igualdad formal) y la realidad material del valor del voto (igualdad real) se produce como consecuencia del territorio. El territorio dividido en circunscripciones electorales para el cómputo de los votos es el elemento de distorsión que rompe la ecuación de representatividad en los sistemas electorales proporcionales.

Tercera. Los votos no tienen un valor cuantitativo igual cuando se materializan en escaños. Es más, el valor no es "semejante" ni "similar" como establecía el Tribunal Constitucional en su conformación del derecho a la igualdad en el sufragio, sino que podría calificarse de "desigual". Se constata que hay una desviación muy elevada entre las circunscripciones muy pobladas respecto a las poco pobladas. La diferencia en el valor de resultado de sufragio llega a ser cinco veces mayor si atendemos al criterio territorial. Si la comparativa se hace en relación al valor del escaño en número de votos para los partidos políticos, la desviación es aún mayor, alcanzando el coeficiente multiplicador de nueve.

Cuarta. A pesar de la interpretación de la proporcionalidad por el Tribunal Constitucional como un criterio orientativo o tendencial, los resultados que arroja la materialización del voto en escaños en las últimas elecciones celebradas en España no parecen tolerables desde la perspectiva de la literalidad del texto constitucional que exige la proporcionalidad del sistema electoral.

Quinta. En consecuencia, la relación de representatividad entre el cuerpo electoral y las candidaturas electas sufre una merma considerable que impide desarrollar la función dinámica de la representación, reflejando las necesidades de la sociedad. 